\section{Recovery of Microbial Polysaccharide B-1459 with a Quaternary Ammonium Compound}

A NEW cyclic process has been developed for isolating a microbial polysaccharide from fermented broth. The usual method has been by addition of a water-misciblo solvent in which the polysaceharide is insoluble, for example, methanol or ethanol ${ }^{1,2}$. Because of the high viscosity of most microbial polymers in water solutions, it is difficult to obtain concentrations greater than 1.5 per cent in the fermented broth; consequently, large amounts of solvent are required to isolate and purify the polysaccharide.

In the new process a polyanion polysaccharide was isolated from fermented broth with a quaternary ammonium compound, and the quaternary ammonium compound recovered and re-used in a cyclic procedure, thereby decreasing the amount of solvent required for isolation. The polysaccharide isolated was synthesized by the bacterium Xanthomonas cam. pestris NRRL $B-1459$ by fermentation of a medium contrining glucose, organic nitrogen, and inorganic salts. At the completion of fermentation, the broth had a viscosity of 7,000 centipoises (determined by means of a Brookfield viscometer); (mention of firm names or trade products does not imply that they are endorsed or recommended by the Department of Agriculture over other firms or similar products not mentioned) and a polysaccharide content of about 1.5 per cent.

Tests showed that the quaternary ammonium compound would be most effective for recovery of polysaccharide in dilute broth in the presence of an electrolyte, such as potassium chloride. Dilution of the broth also facilitated removal of cells and insoluble materials.

Percentages of potassium chloride and quaternary ammonium compound stated in the recovery procedure are based on the weight of undiluted broth.

The broth was diluted to a viscosity of $450 \mathrm{cp}$. by addition of two parts by weight of water, and the cells removed by centrifugation. Two per cent potassium chloride was added to the centrifugate and the poly. saccharide precipitated with 2.75 per cent $(v / w)$ of 'Arquad 16-50', an industrial grade quaternary ammonium compound, which consists primarily of cetyltrimethylammonium chloride. Electrolyte concentration was critical since addition of 1 per cent potassium chloride gave a voluminous gel-like precipitate; whereas with 3 per cent potassium chloride, no precipitate formed.

A fibrous, slowly settling, precipitate formed and was separated from the broth by centrifugation at $13,000 \mathrm{~g}$. The weight of the cake was about 8 per cent of the original broth weight. The centrifuged liquid contained about 2 per cent of the quaternary ammonium compound used, as assayed by the method of Colichman ${ }^{3}$.

To remove the quaternary ammonium compound from the polysaccharide, the cake was agitated with four times its weight of methanol containing 0.05 per cent potassium chloride to prevent gelling in the methanol. The cake filtered easily on a vacuum filter. A total of three washes was made, after which the water-soluble polysaccharide was vaccum dried.

The combined filtrates from the methanol washes were concentrated under vacuum to recover methanol in the distillate and 'Arquad 16-50' in the concentrate. Distillate from the concentration contained 97 per cent methanol. Concentrate from the evaporation was assayed for the quaternary ammonium compound by determining the efficacy of precipitation on poly. saccharide broth samples. The concentrate contained 80 per cent of the original quaternary ammonium eompound. Consequently, 20 per cent of the original amount of fresh quaternary ammonium compound was added to the recovered concentrate for precipitation of polysaccharide from broth in the second cycle. A total of six cycles was made in this manner. Recovery of quaternary ammonium compound after each cycle was 80 per cent.

Table 1. Whight and VIscosity OF WATER SOLUTIONS OF POLY. SACCHARIDE RECOVERED WTTH RE-CYCLED QUATFRNARY AMMONIOM

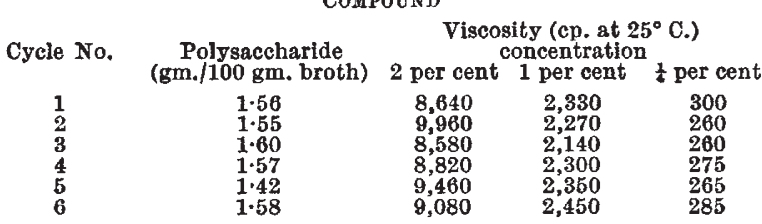

The weight of polysaccharide recovered from each cycle was uniform, except for an unexplained lower recovery on the fifth cycle; and viscosities of water solutions of the polymer showed little variation (Table 1). These viscosities compare favourably with those of polysaccharides recovered by methanol precipitation.

\section{W. J. ALBRECHT \\ S. P. Rogovin \\ E. L. GRIFFin, JUN.}

Northern Regional Research

and Development Division,

Agricultural Research Service, Peoria, Illinois.

${ }^{2}$ Rogovin, S. P., Anderson, R. F., and Cadmus, M. C., J. Biochem Microbiol. Technol. Eng., 3, 51 (1961).

${ }^{2}$ Rogovin, S. P., Sohns, V. E., and Griffin, E. I., Indust. Eng. Chem., 53,37 (1961).

${ }^{3}$ Colichman, E. L., Analyt. Chem., 18, 430 (1947).

\section{Urea Cycle and Cellular Deoxyribonucleic Acid Content}

WHIrE preparing a manuscript on the metabolism of Amphibia to appear in a forthcoming book ${ }^{1}$, I was struck by an interesting relationship between the occurrence of the ornithine-urea cycle ${ }^{2}$ in the liver of vertebrates and the deoxyribonucleic acid (DNA) content of their somatic cells.

Vendrely ${ }^{3}$ has tabulated the values of the DNA content per somatic cell for 73 species of vertebrates. Values ranged, for example, from $0.94 \times 10^{-12} \mathrm{gm}$. DNA per somatic cell in the shad, Eucinostomus gula, to $168 \times 10^{-12} \mathrm{gm}$. in the amphibian, Amphiuma sp. With sevoral exceptions (wood turtle, snapping turtle, alligator, water snake, mouse, and the lamprey eel, all of which exhibited values of $5 \cdot 0 \pm 0 \cdot 1 \times 10^{-12} \mathrm{gm}$.) the urea cycle occurs in, and only in, those verteurates $^{4,5}$ containing more than $5 \cdot 0 \times-10^{-12} \mathrm{gm}$. DNA per nucleus of somatic cell. That is to say, animals examined, the livers of which are capable of effecting a synthesis, de novo, of urea, that is, from carbon dioxide and ammonia, generally possessed nuclear DNA values above a cut-off value of $5 \cdot 0 \times 10^{-12} \mathrm{gm}$.; animals incapable of effecting this synthesis generally had values below the cut-off value (Table 1). Because of the difficulties in determining precise values for the DNA content per cell, it is not certain whether or not there is an overlap of cellular DNA content and the 